\title{
Designing Scarf through Hand Painting Using Sculptures of Sahastrabahu Temple
}

\author{
Chhavi Joshi* and Sudha Babel
}

Department of Textile and Apparel Designing, College of Community and Applied Science, MPUAT Udaipur, India

*Corresponding author

\section{A B S T R A C T}

\section{Keywords}

Hand Painting,

Sculpture,

Design, Scarf,

Sahastrabahu

Temple

\section{Article Info}

Accepted:

12 September 2020

Available Online:

10 October 2020
Painting as an art form has flourished in India from very ancient period. The unique thing about Indian painting is that they are usually representative and connected to highly significant religious forms as culture events. Present study was undertaken with the objectives of documentation of design from sculpture of Sahastrabahu Temple and to develop scarf through hand painting. Sixty best, well maintained and preserved motifs from sculptures of Sahastrabahu Temple was collected designed and developed through software. On basis of relative ranking by 20 experts, top 30 designs was selected from 60 motif and designs, among 30 designs , 20 placement was further developed and used for the preparation of scarf through hand painting. Data on percentage distribution by panel members for suitability of design placements for scarf revealed that placement code 2 got $1^{\text {st }}$ rank $(91 \%)$ on five point rating scale, the experts rated it excellent out of 20 placements. It is concluded that all 5 scarf developed using motif/ design obtain Sahastrabahu Temple were very innovative, creative and distinctive in terms of designs and highly acceptable by panel members.

\section{Introduction}

India has always been known as the land that portrays cultures and traditional vibrancy through its conventional art and craft. Its rich heritage of tradition is reflected in many aspects such as art, costumes, textiles and embroideries of various region of country. Each state of India has its own tradition and legacy of traditional folk art and craft.

Sahastrabahu Temple is located in Nagda village of Udaipur district. The temple of
Lord Vishnu was constructed first, it was named Sahastrabahu Temple. The temple was constructed sometime in the 10th or 11th century A.D by a certain king Mahipala of Kachchhwaha Dynasty. It is a commonly held belief that the queen of Mahipala was a devotee of Lord Vishnu. The temple structure is proof of the sacred nature of family bonds during ancient times.

Textile designing has been an ancient art and perhaps the most ancient craft of India. It is the most demanding and emerging field as it 
is full of scope and creativity. Any objects or things we see in our daily routine are possible design sources.

Painting as an art form has flourished in India from very ancient period. The unique thing about Indian painting is that they are usually representative and connected to highly significant religious forms as culture events. The rural folk paintings of India bear distinctive colorful designs, which are treated with religious and mystical motifs. Hence, the present investigation was conducted with the objective to adapt and develop motifs and designs from the Sculpture of Sahastrabahu temple. For the promotion of the traditional art, the researcher was designed and developed various innovative value added scarf.

\section{Materials and Methods}

\section{Collection of motif}

Various beautiful motifs and designs were carved on the pillars, interior and exterior walls ceilings, domes of Sahastrabahu Temple but owing on the numerous invasions and the effect of time, some portion of this temple are ruined. Sculptures were critically analyzed by the researcher for the selection of suitable motifs for scarf. Sixty best, well maintained and preserved motifs and designs were collected by the researcher for the present investigation.

\section{Documentation of motif on computer using corel draw and development of designs from sculpture of temple}

Total 60 selected Motif and design obtained from sculptures was designed and developed through software On the basis of relative ranking by the experts, top scored 30 designs was selected from 60 motifs and designs. Among 30 designs, 20 placements were further designed and developed for development of scarf. Top scored 5 placement designs were used for the preparation of innovative value added scarf based on the rating of panel members.

\section{Development of products}

Selected 5 placements of motifs and their design combinations were applied on fabric by hand painting techniques using acrylic colour in laboratory and 5 designs of scarf prepared.

\section{Results and Discussion}

\section{Selection of design}

Sixty developed designs comprised of floral and geometrical pattern, motifs of lord Vishnu and Shiva were arranged in line from motif code no. 1 to 60 and then presented before 20 panel members for evaluation of their suitability for developing scarf. A 5 point rating scale was given to each expert and was asked to rate motifs and designs on given criteria. On the basis of relative ranking given by the experts, top scored 30 designs was selected from these 60 motifs and designs.

Data presented in Figure 1 depicts a percentage distribution of 30 most suitable motifs for development of scarf ranging from $62-91 \%$. Among these, it was recorded to be lower for motif code no. 1(62\%) and higher value was measured for motif code no. 30(91 $\%)$.

Similar study was also conducted by Rani et al., (2013) for the development of Saris using Chinese motifs through screen printing. They identified 31 Chinese motifs (eleven geometrical, twelve floral and eight animal motifs) for application on Saris using Corel Draw software. All motifs were evaluated by thirty experts and among them; five top 
ranked motifs were selected from each category for further application.

\section{Development of design and their placements}

Selected 30 motifs were further used to develop Designs placements on scarf and 20 design placements were prepared and presented before 20 panel members for evaluations.

On the basis of relative ranking by the experts, 5 best design placements were used for the preparation of innovative value added scarf. The percentage distribution by panel members for suitability of design placements for scarf are given in figure 2.

A perusal of Figure 2 on percentage distribution by panel members for suitability of design placements for scarf reveals that placement code 2 got $1^{\text {st }}$ rank $(91 \%)$ on five point rating scale, the experts rated it excellent out of 20 placements. Similarly, placement code no. 5, 3, 1 and 6 got $2^{\text {nd }}, 3^{\text {rd }}$, $4^{\text {th }}$ and $5^{\text {th }}$ ranks respectively.

Fig.1 Percentage distribution by the panel members for suitability of motifs for scarf. $(n=20)$

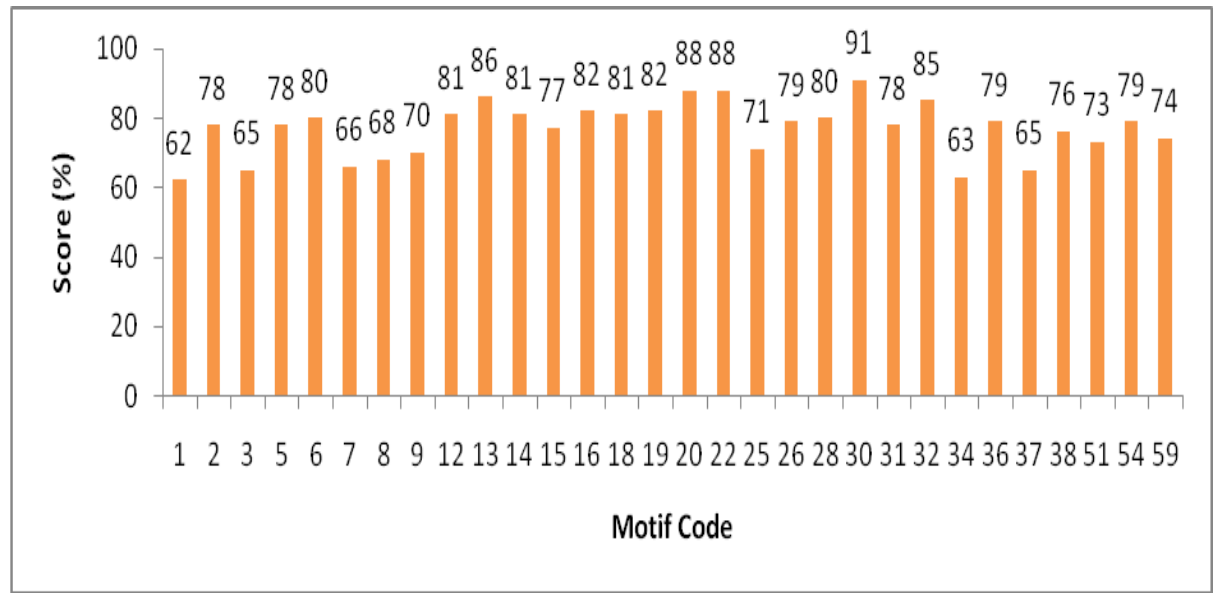

Fig.2 Percentage distribution by panel members for suitability of design placements for scarf. $(n=20)$

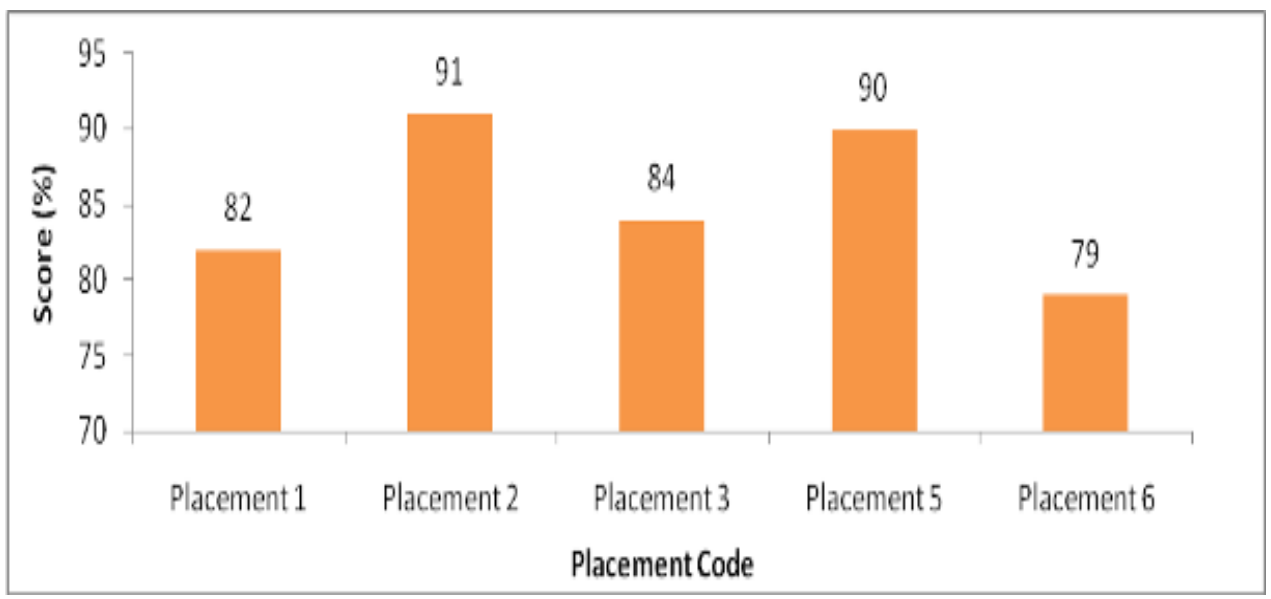


Top 30 Motif for scarf

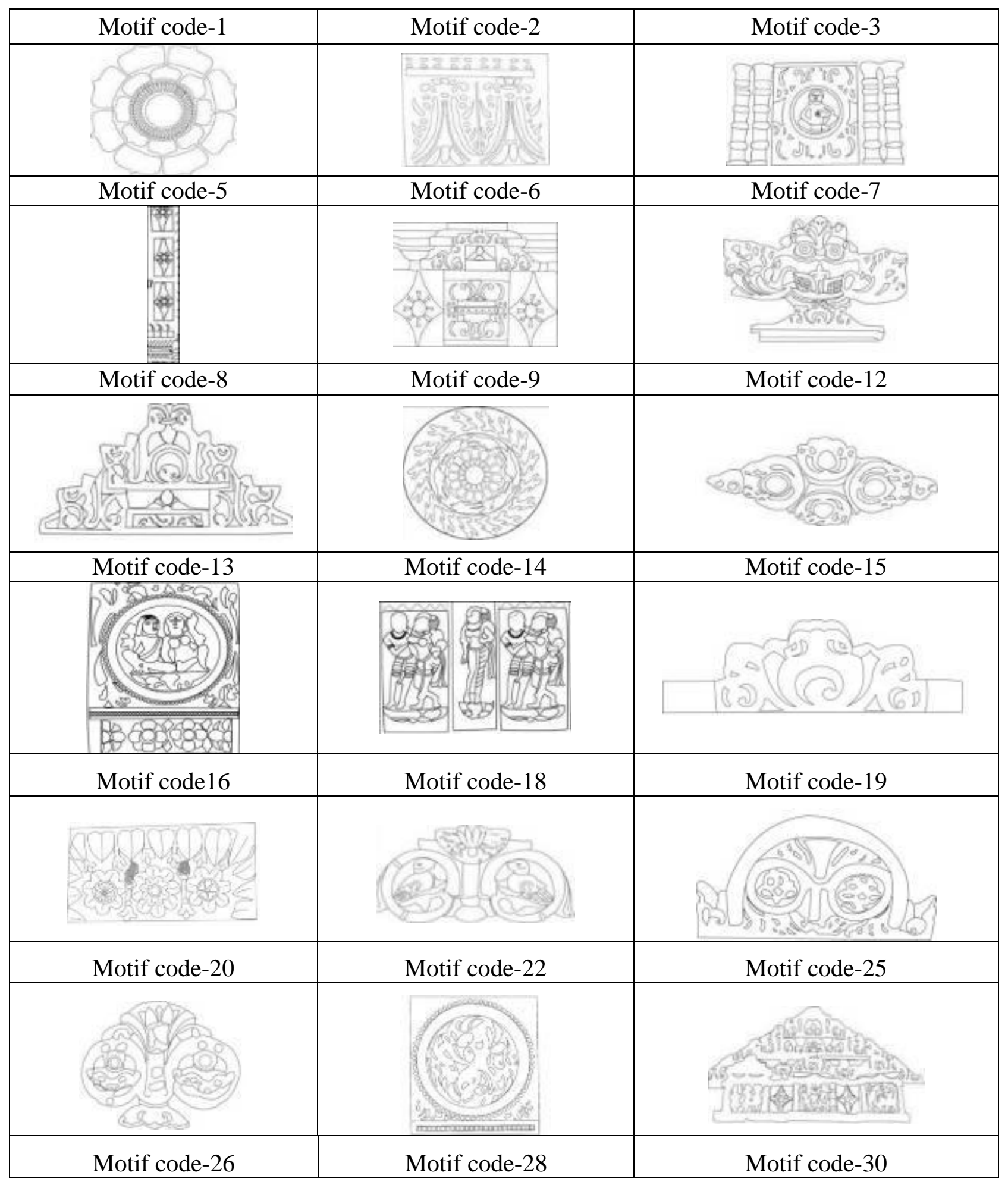




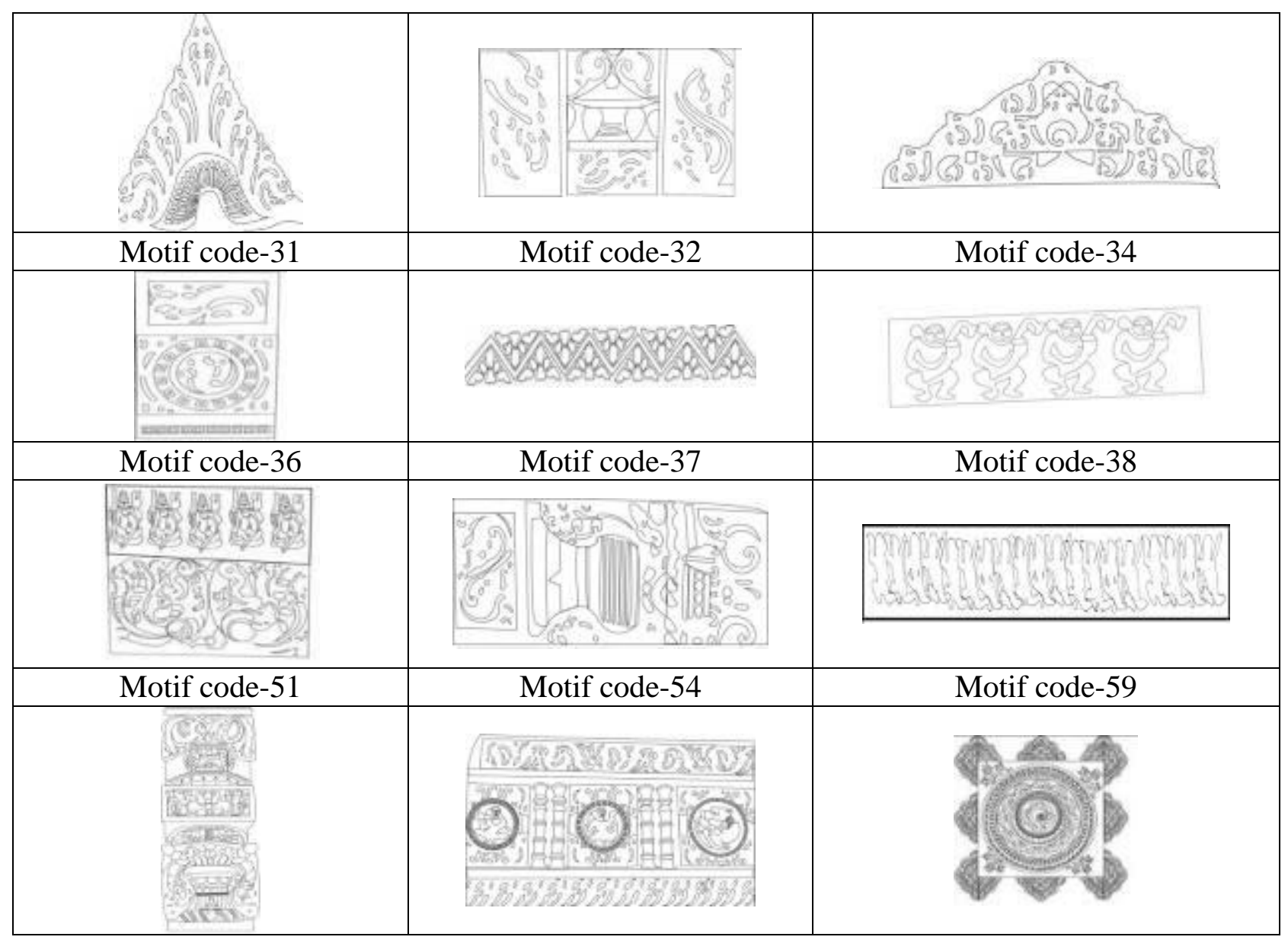

Placement of scarf

\begin{tabular}{|c|c|c|}
\hline Placement code-1 & Placement code -2 & Placement code -3 \\
\hline 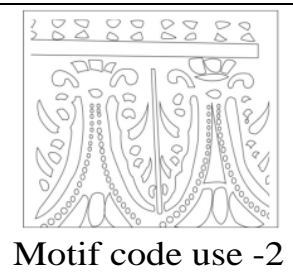 & 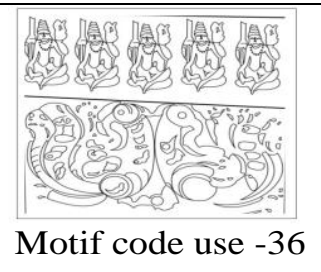 & Motif code use -59 \\
\hline
\end{tabular}

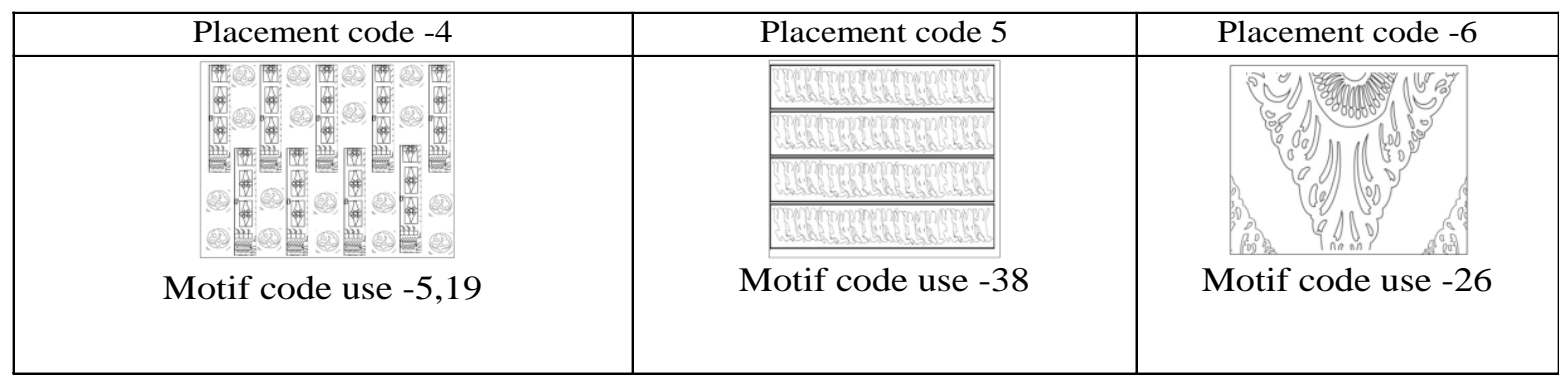




\begin{tabular}{|c|c|c|}
\hline Placement code -7 & Placement code -8 & Placement code -9 \\
\hline 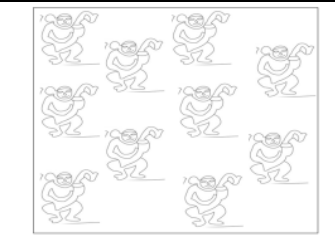 & 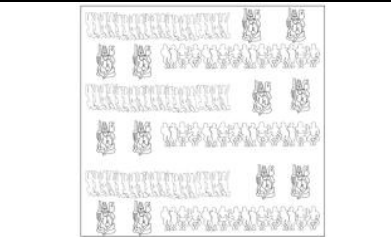 & 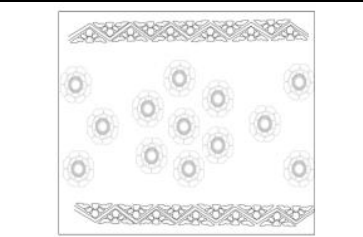 \\
\hline Motif code use -34 & Motif code use $-36,38$ & Motif code use $-1,32$ \\
\hline
\end{tabular}

\begin{tabular}{|c|c|c|}
\hline Placement code -10 & Placement code -11 & Placement code -12 \\
\hline & & \\
Motif code use -12 & Motif code use -22,28 & Motif code use -3,9 \\
\hline
\end{tabular}

\begin{tabular}{|c|c|c|}
\hline Placement code -13 & Placement code -14 & Placement code -15 \\
\hline (39) & 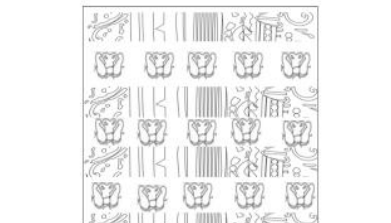 & 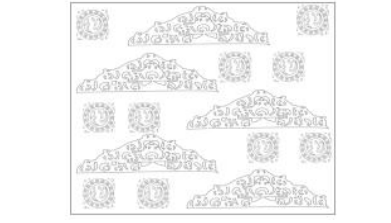 \\
\hline Motif code use $-13,15$ & Motif code use $-37,51$ & Motif code use $-30,31$ \\
\hline
\end{tabular}

\begin{tabular}{|c|c|c|}
\hline Placement code -16 & Placement code -17 & Placement code -18 \\
\hline & & \\
Motif code use $-18,22,25$, & Motif code use $-5,6$ & \\
\hline
\end{tabular}

\begin{tabular}{|c|c|c|}
\hline Placement code -19 & & Placement code -20 \\
\hline & & \\
Motif code use -20,54 & & Motif code use $-14,16$ \\
\hline
\end{tabular}




\begin{tabular}{|c|r|r|}
\hline Developed scarf & Placement code no.3 \\
\hline Placement code no.1 & Placement code no.2 & \\
\hline Placement code no.5 & & \\
\hline Motif code use-2 & Motif code use-36 & Motif code use-59 \\
\hline Motif code use-38 & & Placement code no.6 \\
\hline & & Motif code use-26 \\
\hline
\end{tabular}

\section{Development of scarf}

Selected 5 placement of motif and their design combination were applied on scarf by hand painting techniques using acrylic colour.

It can be concluded that idea of bringing about innovation with hand painting can be useful as self employment project by using them in making different designs of scarf for sale through boutiques or retailers and also a good effort to boost the self creativity. It would prove bright future in field of handicrafts.

\section{References}

Rani,P., Rose, N.M. Singh, J., and Yadav, S.2013. Development of screen printing designs for saree using Chineese motifs. Asian Journal of Home Science. 8(1): 175179.

Sharma E. (2015) Tribal Folk Arts of India, Journal of International Academic Research For Multidisciplinary. 3(5): 300308.

https://en.wikipedia.org/wiki/Sahastra_Bahu_ Temples

\section{How to cite this article:}

Chhavi Joshi and Sudha Babel. 2020. Designing Scarf through Hand Painting Using Sculptures of Sahastrabahu Temple. Int.J.Curr.Microbiol.App.Sci. 9(10): 1295-1301.

doi: https://doi.org/10.20546/ijcmas.2020.910.156 